\title{
Einkorn (Triticum monococcum ssp. monococcum) in vitro propagation sterilization protocol
}

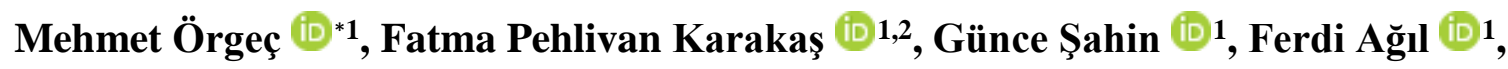 \\ Nusret Zencirci (iD) 1
}

${ }^{1}$ Abant Izzet Baysal University, Department of Biology, Faculty of Science and Art, Bolu
${ }^{2}$ Abant Izzet Baysal University, Department of Field Crops, Faculty of Agriculture and Natural Sciences, Bolu

\begin{abstract}
Einkorn is one of the oldest and important wheat species because of its increasing economic value, agronomical technical properties, and health and sanitary effects. Therefore, a faster tissue culture production protocol which may ensure a fast einkorn production is desired. The tissue culture process first requires an efficient sterilization technique of the explant to eliminate contamination factors in this hulled species. In this study, we, thus, aimed to determine the effective einkorn sterilization process for the removal of contaminating microorganisms without the loss of germination capacity and viability. We tested 22 following sterilant combinations with different concentration and exposure time: Ethanol, Commercial Bleach, Tween 20, Mercury (II) Chloride, and Sterile Distilled Water. On the other hand, obtained the data were analyzed by one-way ANOVA and Duncan test, where $\mathrm{p} \leq 0.05$ was accepted significant. Forty percent commercial bleach which were applied fifteen minutes eliminated all microorganisms with a $92.6 \%$ seed germination. The second-best technique was one minute exposure of $70 \%$ ethanol which were followed by 10 minutes exposure of $20 \%$ commercial bleach. This assured up to $89 \%$ germination and no contamination. The worst results came from the mercury (II) chloride with $0 \%$ contamination and $\leq 25 \%$ germination rate. Mercury (II) Chloride was both highly toxic on the seeds and reduced the contamination. Commercial Bleach and Ethanol Chemicals were less toxic while providing an acceptable sterilization.
\end{abstract}

\section{ARTICLE HISTORY}

Received: 18 January 2018

Revised: 17 February 2018

Accepted: 26 February 2018

\section{KEYWORDS}

Contamination,

Einkorn wheat,

Germination,

Seed sterilization,

Tissue culture

\section{Introduction}

Wheat (Triticum aestivum L.) of Poaceae family grows in the most parts of the world. It was first cultivated more than ten thousand years ago in the Fertile Crescent. Nowadays, it is the second largest annual crop produced and consumed ( 700 million tons), which supplies about $20 \%$ of the world's calories [1] and a major amount of protein. Biotic (fungal, bacterial, etc.) and abiotic (salt, cold, etc.) stresses, on the other hand, cause serious yield losses in wheat production. Therefore, efforts to sustain the wheat production through the application of new approaches including tissue culture are considered to be desired alternative approaches. 
Einkorn (Triticum monococcum ssp. monococcum) is the first cultured hulled wheat species. Its domestication dates back to 9,000 B.C in Turkey. Einkorn is the most basic wheat form because of its diploid chromosome number $(2 n=14)$. Einkorn is, currently, cultivated in mountainous areas of Turkey, Greece, Bulgaria, Yugoslavia, and Italy at smaller quantities [2, 3]. Einkorn, with its low glycemic index, is a good food agent against the chronic diseases, cancer(s), obesity, diabetes, etc. In addition, it has more lutein than that of Triticum aestivum L., which prevents skin, eyes, and cardiovascular health problems $[4,5]$.

In vitro plant culture "which encompasses cell, tissue, organ, and also embryo culture", is a vital technique for mass multiplication of plants, elimination of plant diseases through meristematic tissue culture technique, plant conservation, and crop improvement through gene transfer" [6]. Fundamentally, plant culture technique consists of transferring different pieces of a plant (such as a stem tip, plantlet, scutellum, node, meristem, embryo, coleoptile or even a seed) and whole plant into a sterile nutrient medium where they multiply [7]. However, the success of plant tissue culture process strictly depends on efficient explant sterilization protocol. During plant tissue culture process, contaminations are the most serious problems which cause to losses by microorganism in explant sources. These microorganisms include viruses, bacteria, fungi, yeast, etc. Nutrient media in which the plant pieces are planted have also good source for microbial growth. These microorganisms compete hard with the plant material for nutrient in the media [7]. The presence of these microbes in the plant cultures process usually results in increased culture mortality, lowered growth, tissue necrosis, reduced shoot proliferation, and reduced rooting [8].

There are a lot of common sterilants for the surface sterilization of plant material. Popular disinfectants are sodium hypochlorite, ethanol, mercuric chloride, calcium hypochlorite, silver nitrate, hydrogen peroxide, bromine water, and Tween 20 [9]. However, many sterilants can be toxic to the plant tissues, because of their concentrations, their exposure duration to the explants or their process sequence, etc. [10]. Hence, the efficient plant tissue culture processes start use with an optimal sterilization technique. The choice of time period and chemical agents depend on the sensitivity of the explant to be sterilized. Because, the preferred procedure for sterilization eliminate all microorganisms on one hand kill the plant tissue on the other hand. The biological activity in the explant sources should be protected during the sterilizations process as well. Therefore, it is important to determine the optimal conditions for each plant species, tissues and explant types.

Up to now, there are no study reports about the surface sterilization process of einkorn wheat. Hence, the aim of this study was to determine the best sterilization protocol for in vitro propagation process of einkorn (Triticum monococcum ssp. monococcum) wheat at the Abant İzzet Baysal University, Biology Department, Plant Genetics \& Pathology Laboratory, Bolu, Turkey in 2017.

\section{Material and Methods}

\subsection{Seed source}

The seeds of einkorn (Triticum monococcum ssp. monococcum) in this study were get from Seben (Bolu) District in the 2015/2016 at the harvest and all the experiments were conducted at the Abant Izzet Baysal University, Biology Department, Plant Genetics \& Pathology Laboratory, Bolu, Turkey in the 2017.

\subsection{Surface sterilization of einkorn seed}

Tween 20 (Sigma), Commercial Bleach-Domestos (4.6\% NaClO), Ethanol (Merck), Mercuric Chloride (Sigma) were used in this study. Used sterilants were applied at different concentrations, methods, and exposure times. Totally, 22 different sterilization methods were applied. In all methods, einkorn wheat explants were washed for one minute by distilled water 
in which 5 drops of Tween 20 were poured into $100 \mathrm{ml}$ at the beginning (Table 1). The variables were with or without $70 \%$ Ethanol, Domestos $20 \%, 30 \%$, or $40 \%$ for 10 or 15 minutes, Mercury Chloride $0.1 \%$ or $0.3 \%$ for 10 or 15 minutes. The labware (beakers, pens, water etc.) was sterilized in the autoclave (Nüve OT - 40L) before the experiment. And, hulls of the seeds were dehulled before the sterilization process. Then, the healthy seeds were selected before and after the surface. Used seeds were washed 3 times with sterile water and then pl anted into petri plates. All sterilizations processes were realized in the laminar airflow chamber (Nüve LN 090). All variables were repeated 3 times.

Table 1. Twenty-two diverse surface sterilization methods for einkorn wheat in this study.

\begin{tabular}{|c|c|c|c|c|}
\hline Methods & Ethanol & Commercial Bleach & Mercury (II) Chloride & Sterilized Water \\
\hline 1 & -- & $20 \%$ Domestos $-10 \mathrm{~min}$ & -- & -- \\
\hline 2 & $70 \%$ Ethanol - $1 \mathrm{~min}$ & $20 \%$ Domestos - $10 \mathrm{~min}$ & -- & -- \\
\hline 3 & -- & $30 \%$ Domestos $-10 \mathrm{~min}$ & -- & -- \\
\hline 4 & $70 \%$ Ethanol - $1 \mathrm{~min}$ & $30 \%$ Domestos $-10 \mathrm{~min}$ & -- & -- \\
\hline 5 & -- & $40 \%$ Domestos - $10 \mathrm{~min}$ & -- & -- \\
\hline 6 & $70 \%$ Ethanol - $1 \mathrm{~min}$ & $40 \%$ Domestos $-10 \mathrm{~min}$ & -- & -- \\
\hline 7 & -- & -- & $0.1 \% \mathrm{Hg} 2 \mathrm{Cl}-10 \mathrm{~min}$ & -- \\
\hline 8 & $70 \%$ Ethanol - $1 \mathrm{~min}$ & -- & $0.1 \% \mathrm{Hg} 2 \mathrm{Cl}-10 \mathrm{~min}$ & -- \\
\hline 9 & -- & -- & $0.3 \% \mathrm{Hg} 2 \mathrm{Cl}-10 \mathrm{~min}$ & -- \\
\hline 10 & $70 \%$ Ethanol - $1 \mathrm{~min}$ & -- & $0.3 \% \mathrm{Hg} 2 \mathrm{Cl}-10 \mathrm{~min}$ & -- \\
\hline Control & -- & -- & -- & $100 \mathrm{ml} \mathrm{sdw}-10 \mathrm{~min}$ \\
\hline 12 & -- & $20 \%$ Domestos - $15 \mathrm{~min}$ & -- & -- \\
\hline 13 & $70 \%$ Ethanol - $1 \mathrm{~min}$ & $20 \%$ Domestos - $15 \mathrm{~min}$ & -- & -- \\
\hline 14 & -- & $30 \%$ Domestos - $15 \mathrm{~min}$ & -- & -- \\
\hline 15 & $70 \%$ Ethanol - $1 \mathrm{~min}$ & $30 \%$ Domestos - $15 \mathrm{~min}$ & -- & -- \\
\hline 16 & -- & $40 \%$ Domestos - $15 \mathrm{~min}$ & -- & -- \\
\hline 17 & $70 \%$ Ethanol - $1 \mathrm{~min}$ & $40 \%$ Domestos - $15 \mathrm{~min}$ & -- & -- \\
\hline 18 & -- & -- & $0.1 \% \mathrm{Hg} 2 \mathrm{Cl}-15 \mathrm{~min}$ & -- \\
\hline 19 & $70 \%$ Ethanol - $1 \mathrm{~min}$ & -- & $0.1 \% \mathrm{Hg} 2 \mathrm{Cl}-15 \min$ & -- \\
\hline 20 & -- & -- & $0.3 \% \mathrm{Hg} 2 \mathrm{Cl}-15 \mathrm{~min}$ & -- \\
\hline 21 & $70 \%$ Ethanol - 1 min & -- & $0.3 \% \mathrm{Hg} 2 \mathrm{Cl}-15 \mathrm{~min}$ & -- \\
\hline Control & -- & -- & -- & $100 \mathrm{ml} \mathrm{sdw}-15 \mathrm{~min}$ \\
\hline
\end{tabular}

All methods were washed first with 5 drops of Tween 20 into $100 \mathrm{ml}$ distilled water for one minute, Sdw; Sterilized distilled water.

\subsection{Germination media and cultivation conditions}

The germination of einkorn wheat seeds was induced on $4.4 \mathrm{~g} / 1$ Murashige and Skoog (Murashige and Skoog 1962) nutrient medium (Duchefa) supplemented with $30 \mathrm{~g} / \mathrm{l}$ sucrose (Merck) and $8 \mathrm{~g} / \mathrm{l}$ plant Agar (Duchefa). The $\mathrm{pH}$ of all media was adjusted between (5.7-5.8) using $1 \mathrm{~N} \mathrm{HCl}$ and $1 \mathrm{~N} \mathrm{NaOH}$ before autoclaving [11]. UV light in the laminar flow was switched on 15 minutes before seeds were planted into the media. All cultures were incubated in the growth room under $16 \mathrm{~h}$ light $8 \mathrm{~h}$ dark at $23 \pm 2{ }^{\circ} \mathrm{C}$ and $60-70 \%$ relative humidity for 10 days [12]. Germination of einkorn wheat seeds started within 4-5 days after planted, and 10 days later germination and contamination rates were calculated [10]. 


\subsection{Statistical analysis}

The germination percentage was measured in each petri after 10 days and analyzed by SPSS software version 24. Analysis of variance (ANOVA) test was performed and mean comparison was carried by Duncan's multiple range test $(p<0.05)$ [13]. Contamination percentage was, on the other hand, calculated using Microsoft Office Excel Worksheet [10].

\section{Findings}

During this study, various surface sterilizing materials were applied by different methods at different concentrations and exposure times to determine the most efficient sterilization procedure without the loss of germination capacity in hulled einkorn wheat. Twenty-two different surface sterilization methods were evaluated for seeds of einkorn wheat and described in Table 1. Since an efficient sterilization protocol of einkorn wheat may accelerate the success in future tissue culture studies sterilization of explant in tissue culture is the first important step.

The best germination percentage was realized in 10 minutes group with the sterilization method $2(89.00 \%)$. Sterilization method 6 had also a good germination percentage of $86.25 \%$. Sterilization method 8, 9, and $10 \mathrm{had}$, on the other hand, ended up with the lowest germination percentage of $1.75 \%, 1.75 \%$, and $0 \%$, respectively (Figure 1). The highest contamination in 10 minutes group developed in the control group and sterilization method 6: $100 \%$ and 20\%, respectively. Sterilization methods $2,7,8,9$, and 10 did not have in any contamination (Figure $3)$.

Table 2. Germination and contamination percentages of Einkorn (Triticum monococcum ssp. monococcum) wheat.

\begin{tabular}{ccc}
\hline Method & Germination $(\%)$ & Contamination $(\%)$ \\
\hline 1 & $74.62 \% \pm 4.08^{\mathrm{bcd}}$ & $5.5 \%$ \\
2 & $89 \% \pm 2.93^{\mathrm{abc}}$ & 0 \\
3 & $61.97 \% \pm 4.03^{\mathrm{de}}$ & $5.8 \%$ \\
4 & $61.62 \% \pm 6.24^{\mathrm{de}}$ & $17.6 \%$ \\
5 & $58.92 \% \pm 6.85^{\mathrm{de}}$ & $17.6 \%$ \\
6 & $86.25 \% \pm 2.31^{\mathrm{abc}}$ & $20 \%$ \\
7 & $25 \% \pm 6.45^{\mathrm{f}}$ & 0 \\
8 & $1.75 \% \pm 1.25^{\mathrm{g}}$ & 0 \\
9 & $1.75 \% \pm 0.25^{\mathrm{g}}$ & 0 \\
10 & $0^{\mathrm{g}}$ & 0 \\
11 & $61.25 \% \pm 3.14^{\mathrm{de}}$ & $100 \%$ \\
12 & $52.5 \% \pm 4.33^{\mathrm{e}}$ & 0 \\
13 & $97.08 \% \pm 1.14^{\mathrm{a}}$ & $20 \%$ \\
14 & $92.14 \% \pm 3.50^{\mathrm{ab}}$ & $6.6 \%$ \\
15 & $63.66 \% \pm 4.53^{\mathrm{de}}$ & $11.7 \%$ \\
16 & $92.66 \% \pm 8.83^{\mathrm{ab}}$ & 0 \\
17 & $72.16 \% \pm 4.21^{\mathrm{cd}}$ & 0 \\
18 & $16.66 \% \pm 4.21^{\mathrm{fg}}$ & 0 \\
19 & $10 \% \pm 4.0^{\mathrm{fg}}$ & 0 \\
20 & $0.25 \% \pm 0.2500^{\mathrm{g}}$ & 0 \\
21 & $0^{\mathrm{g}}$ & 0 \\
22 & $61.25 \% \pm 4.26^{\mathrm{de}}$ & $100 \%$ \\
\hline
\end{tabular}

The best germination percentage in 15 minutes group was the sterilization method 13 with $97.08 \%$. Sterilization methods 16 and 14 had almost the same germination level, $92.66 \%$ and $92.14 \%$, respectively. These two methods were the second better techniques (Figure 2). Sterilization methods 20 and 21 had lower germination: $0.25 \%$ and $0.00 \%$, respectively (Figure 
2). Control group and the sterilization method 13 developed the highest contamination in 15 minutes group. Their percentages were $100 \%$ and $20 \%$, respectively. Sterilization methods 12 , 15,16, 17,18,19, 20, and 21 did not produce any contaminations (Figure 4).

The results of all methods showed that, 5 drops of Tween 20 for 1 minute, then $70 \%$ ethanol for 1 minute, and 20\% Domestos (4,6\% NaClO) for 15 minutes (sterilization method 13) were given the best for germination values. The sterilization method 16 had the highest percentages for both (Table 2), if we consider germination and contamination together in one method.

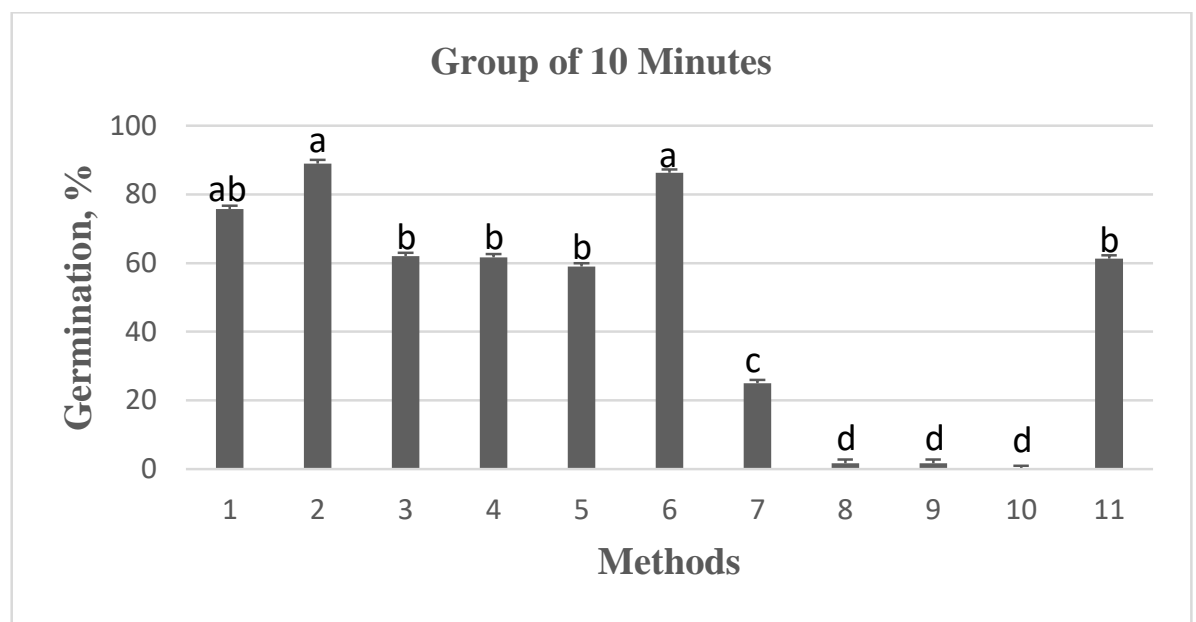

Figure 1. Germination percentage of sterilization methods. 10 minutes exposure to the sterilant. Germination rate measured after 10 days of planted date. Means indicated by different letters differ significantly at $\mathrm{p} \leq 0.05$.

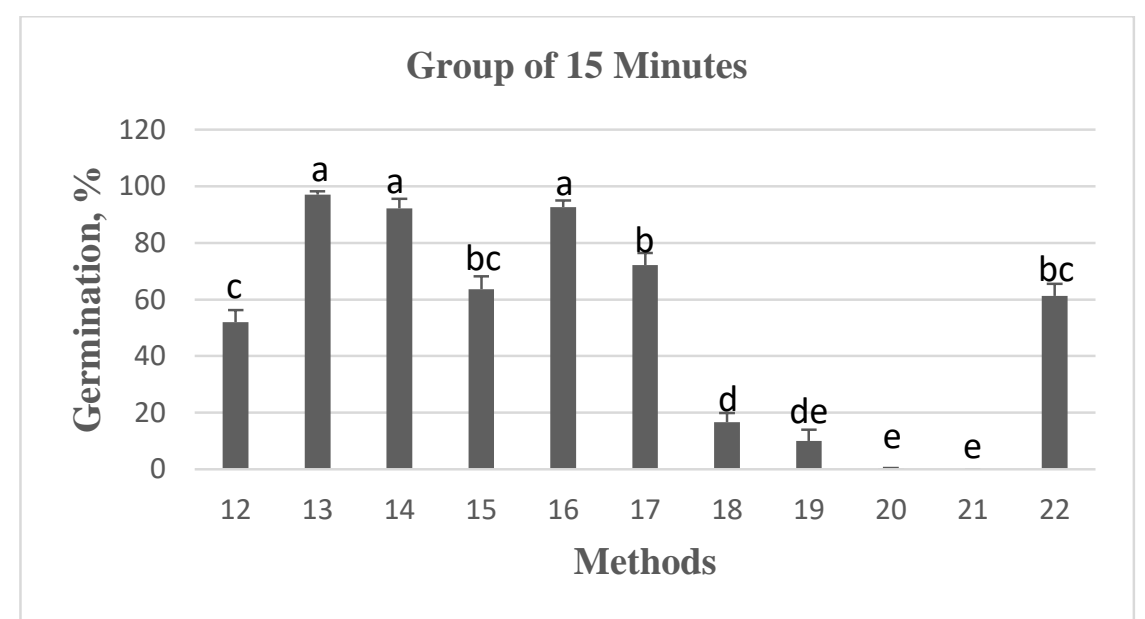

Figure 2. Germination percentage of sterilization methods: 15 minutes of exposure to the sterilant. Germination rate measured after 10 days of planted date. Means indicated by different letters differ significantly at $\mathrm{p} \leq 0.05$. 


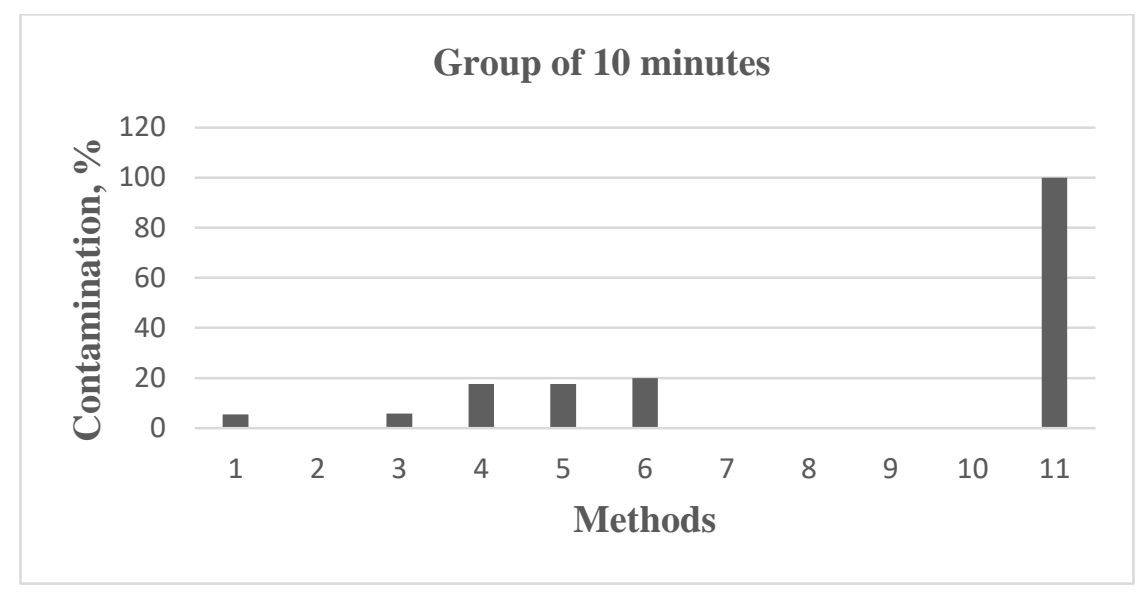

Figure 3. Contamination percentage of sterilization methods: 10 minutes exposure to the sterilant

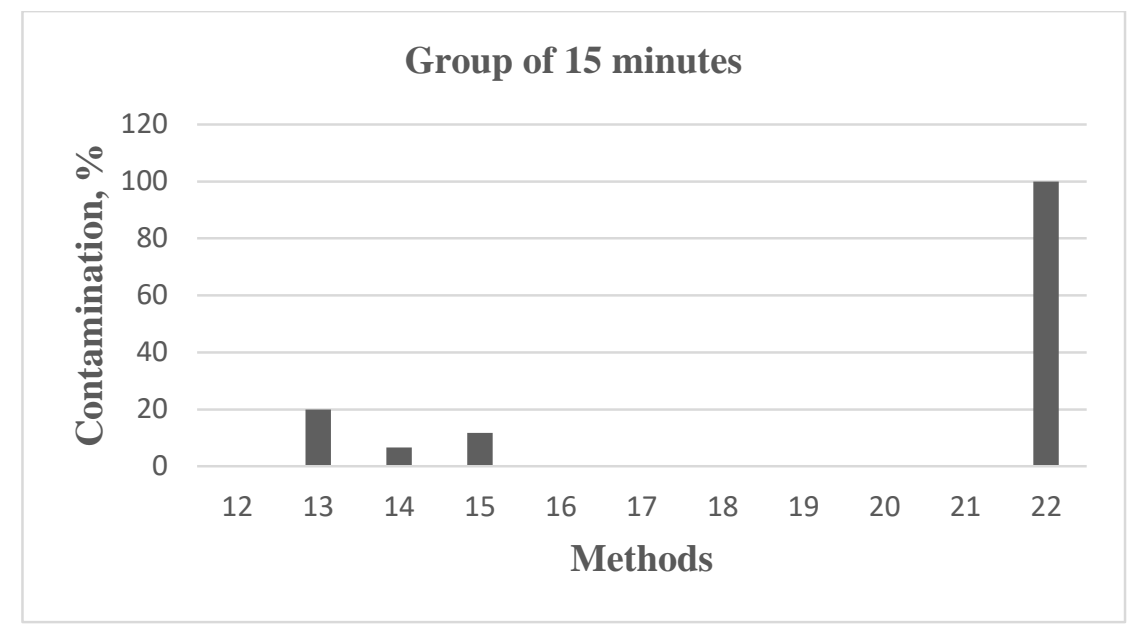

Figure 4. Contamination percentage of sterilization methods: 15 minutes exposure to the sterilant

\section{Discussion and Conclusion}

Tissue culture methods are successfully aided to produce many kinds of plants for commercial and research purposes [13]. During tissue culture procedure, new plants are grown from pieces of explant in a nutrient medium under sterile conditions. Several bacteria and fungi can exist and develop on these plant tissues surfaces. Therefore, it is important that the explants must be free of any microbial contaminants prior to the tissue culture since microorganisms may grow in the culture medium [14]. Thus, this study was performed to determine the best seed sterilization protocol for einkorn wheat. Many techniques in our experiment showed better germination and lower contamination rates. $\mathrm{HgCl}_{2}$ was extensively applied for surface sterilization in tissue culture $[15,16]$. Exposure to $\mathrm{HgCI}_{2}$ decreased the survival rate of explant rate [17]. Our findings supported this statement with the lowest germination rate with the methods included $\mathrm{HgCl}_{2}$. Even small amounts of $\mathrm{HgCI}_{2}$ and shorter exposure time killed almost all einkorn wheat seeds (Figure 1). On the other hand, the methods with $\mathrm{HgCI}_{2}$ did not allow to any contamination. That is probably because of the highly toxic properties of $\mathrm{HgCI}_{2}$ to human, plant, and microorganism. Our result also showed that $\mathrm{HgCI}_{2}$ was toxic to einkorn seeds and severely decreased the germination capacity (Table 2).

The use of $\mathrm{NaClO}$ for surface sterilization of explant sources have been reported in many previous studies as well [18-20]. $\mathrm{NaClO}$ is very common in vitro culture processes because of its simplicity, effectiveness, and cheapness. $\mathrm{NaOCl}$ is, also, highly effective sterilant against all kinds of bacteria, fungi, and viruses. In this study, increased $\mathrm{NaClO}$ amount and exposure time 
amplified the germination and lessened the contamination rates (Methods 2, 14, and 16). On the other hand, Ethanol chemical is known to be powerful but also phytotoxic sterilizing agent. It is usually applied with other chemicals. Two-step sterilization process with ethanol was found to be effective in a previous study [9]. Ethanol with $\mathrm{NaClO}$ in our study also provided the best germination rates (Methods 2 and 13). Of these effective sterilants may provide a good start with einkorn and grain crops similar to einkorn as well and decrease the time loss when a lab starts tissue culture studies for the first time. Obtained results of the study have demonstrated that the use of simple procedure immersion in 5 drop of Tween 20 into $100 \mathrm{ml}$ distilled water for 1 minute, followed by soaking in Sodium Hypochlorite $40 \%$ for 15 minutes is sufficient for the surface sterilization and of einkorn seeds without any loss of germination capacity.

\section{Acknowledgements}

The authors are grateful to the Abant Izzet Baysal University Research Foundation (Project No: BAP-2017.03.01.1130) for their kind financial support.

\section{Orcid}

Mehmet Örgeç (D) https://orcid.org/0000-0002-9446-7538

Fatma Pehlivan Karakaş (D) https://orcid.org/0000-0001-5245-6294

Günce Şahin (D) https://orcid.org/0000-0003-0060-259X

Ferdi Ağ1l (iD https://orcid.org/0000-0003-1685-6711

Nusret Zencirci (iD) https://orcid.org/0000-0003-3460-7575

\section{References}

[1] Ribeiro, M., Poeta, P., \& Igrejas, G. (2014). The Genetic Variability of Wheat Can Ensure Safe Products for Celiac Disease Patients? International Journal of Celiac Disease, 2(1), 24-26.

[2] Zencirci, N., \& Kun, E. (1995). Variation in landraces of durum wheat (T. turgidum L. conv. durum (Desf.) MK) from Turkey. Euphytica, 92(3), 333-339.

[3] Cooper, R. (2015). Re-discovering ancient wheat varieties as functional foods. Journal of Traditional and Complementary Medicine, 5(3), 138-143.

[4] Abdel-Aal, E. M., Young, J. C., Wood, P. J., \& Rabalski, I. (2002). Einkorn: A potential candidate for developing high lutein wheat. Cereal Chemistry, 79(3), 455.

[5] Ozberk, I., Atay, S., Altay, F., Cabi, E., Ozkan, H., \& Atl1, A. (2016). The Wheat Atlas of Turkey WWF-Turkiye, TR: Istanbul.

[6] Mng'omba, S. A., Sileshi, G., Du Toit, E. S., \& Akinnifesi, F. K. (2012). Efficacy and utilization of fungicides and other antibiotics for aseptic plant cultures. Fungicides for Plant and Animal Diseases, InTech. (pp. 245-255).

[7] Odutayo, O. I., Oso, R. T., Akinyemi, B. O., \& Amusa, N. A. (2004). Microbial contaminants of cultured Hibiscus cannabinus and Telfaria occidentalis tissues. African Journal of Biotechnology, 3(9), 473-476.

[8] Nadha, H. K., Salwan, R., Kasana, R. C., Anand, M., \& Sood, A. (2012). Identification and elimination of bacterial contamination during in vitro propagation of Guadua angustifolia Kunth. Pharmacognosy Magazine, 8(30), 93.

[9] Ishfag, S., Ahmed, S. D., Shah, H. A., Khan, R. T., Bukhari, S. M. F., Hameed, I., Mubeen, H., Awan, N., Abbas, S. R., \& Raza, S. (2016). In-Vitro Optimization Protocol of Wheat Cultivars in Newly Established Lab of Plant Culture, Muzaffarad. Euro J Pharma and Med Res, 3(3), 477-479.

[10] Sen, M. K., Jamal, M. A. H. M., \& Nasrin, S. (2013). Sterilization factors affect seed germination and proliferation of Achyranthes aspera cultured in vitro. Environmental and Experimental Biology, 11, 119-123. 
[11] Mehmood, K., Arshad, M., Muhammad, G. A., \& Razzaq A. (2013). Tissue culture responses of some wheat (Triticum aestivum L.) cultivars grown in Pakistan, Pal. J. Bot., 45(SI), 545-549.

[12] Majewsla, M., Sodkiewicz, W., \& Sodiewicz, T. (2007). Callus induction and plant regeneration in propagation of wheat hybrids with introduced $\mathrm{A}^{\mathrm{M}}$ (Triticum monococcum) or R (Secale cereale) genome, Acta Biologica Cracoveinsia Series Botanica, 49(2), 3944.

[13] Hussain, A., Qarshi, I. A., Nazir, H., \& Ullah, I. (2012). Recent Advances in Plant In vitro Culture. In A. Leva \& L. M. R. Rinaldi (Eds.), Plant Tissue Culture: Current Status and Opportunities (pp. 1-28). Intech open access publisher: Croatia.

[14] Guma, T. B., Jane, K., Justus, O., \& Kariuki, P. N. (2015). Standardization of in vitro sterilization and callus induction protocol for leaf explants of anchote: Coccinia abyssinica. International Journal of Research and Development in Pharmacy and Life Sciences, 4(2), 1427-1433.

[15] Naika, H. R., \& Krishna, V. (2008). Plant regeneration from callus culture of Clematis gouriana Roxb-a rare medicinal plant. Turkish Journal of Biology, 32(2), 99-103.

[16] Karakas, F. P., \& Turker, A. U. (2013). An efficient in vitro regeneration system for Bellis perennis L. and comparison of phenolic contents of field-grown and in vitro-grown leaves by LC-MS/MS. Industrial Crops and Products, 48, 162-170.

[17] Danso, K. E., Azu, E., Elegba, W., Asumeng, A., Amoatey, H. M., \& Klu, G. Y. P. (2011). Effective decontamination and subsequent plantlet regeneration of sugarcane (Saccharum officinarum L.) in vitro. Int. J. Integra. Biol., 11, 90-96.

[18] Ozgen, M., Turet, M., Altınok, S., \& Sancak, C. (1998). Efficient callus induction and plant regeneration from mature embryo culture of winter wheat (Triticum aestivum L.) genotypes. Plant Cell Reports, 18(3), 331-335.

[19] Mendoza, M. G., \& Kaeppler, H. F. (2002). Auxin and sugar effects on callus induction and plant regeneration frequencies from mature embryos of wheat (Triticum aestivum L.). In Vitro Cellular \& Developmental Biology-Plant, 38(1), 39-45.

[20] Mitić, N., Dodig, D., \& Nikolić, R. (2006). Variability of in vitro culture response in wheat genotypes, genotype and environmental effects. Genetika, 38(3), 183-192. 